\title{
Using Opportunities to Respond (OTR) to Reduce Disruptive Behavior in General Education Settings
}

\author{
Hassan Alzahrani \\ Assistant Professor, Umm Al-Qura University
}

\begin{abstract}
This paper focuses on externalizing behavior that disrupts the classroom. This behavior causes many difficulties for teachers in their classroom environments and can become distracting for peers, impeding their ability to concentrate inside the classroom. Therefore, teachers must provide an instruction-rich, supportive environment that provides all students with the chance to be appropriately and correctly involved in class proceedings. Such an environment also boosts students' social responsiveness, which in return allows them to limit being affected by distractions. This study used an opportunities to respond (OTR) strategy to address disruptive behavior inside the classroom by applying a single-subject experimental design (SSED). An A-B-A design was used in this study to locate the effect of OTR. The results showed that OTR intervention was effective, and the third phase showed the improvements made by students. Finally, recommendations based on the results from the current study are provided.
\end{abstract}

Keywords: Externalizing behavior, Opportunities To Respond (OTR), Single-subject experimental design.

DOI: $10.7176 / \mathrm{JEP} / 12-33-14$

Publication date: November $30^{\text {th }} 2021$

\section{Introduction}

The Individuals with Disabilities Education Act (IDEA) describes emotional and behavioral disorders (EBD) as conditions that are exhibited by one or more of five specific characteristics to a noticeable degree over an extended period that negatively affect a child's educational performance. The five characteristics are as follows: an inability to learn that cannot be the result of an intellectual disability, a sensory disability, or other health factors; an inability to build or maintain satisfactory interpersonal relationships with peers and teachers; inappropriate behaviors or feelings under normal circumstances; a general, pervasive mood of unhappiness or depression; and a tendency to build up physical symptoms or fears linked to personal or school-related problems (Turnbull, Turnbull, Wehmeyer, \& Shogren, 2016).

According to Seeley, Severson, and Fixsen (2014), the most common diagnoses involved as shown in the above characteristics are anxiety disorders (32\%), followed by disruptive behavior disorders $(19 \%)$, mood disorders $(14 \%)$, and substance-use disorders $(11 \%)$. Since disruptive behavior disorders are one of the most common diagnoses, various stakeholders have addressed noncompliance in disruptive behavior problems as shown in various settings.

This paper focuses on identifying externalizing behavior problems. These behaviors disrupt the classroom environment by causing difficulties for teachers and distractions for peers that impede students with disruptive behaviors and their peers ability to concentrate on instruction (Bradshaw, Buckley, \& Ialongo, 2008). Specifically, this paper concentrates on noncompliant disruptive behavior when a child attempts to avoid finishing a task by playing or doing something else and then neglects to follow an instruction. Student commitment and engagement in classroom activities promote learning and academic achievement, while noncompliant disruptive behavior can result in negative indicators (Jensen, 2018). Noncompliant disruptive behavior in the classroom, if left unaddressed, increases a student's risk of continued behavior problems and poor grades (Finn \& Rock, 1997). The specific behaviors examined in this study are those wherein the students get out of their seats. The operational definition of this behavior is that a student leaves their appointed seat without authorization from the teacher for five or more seconds throughout classroom teaching. This behavior disrupts the classroom environment by causing difficulties for teachers and distractions for peers that impede their ability to concentrate on instruction (Bradshaw et al., 2008).

Specifically, this paper focuses on behaviors in which children attempt to avoid finishing tasks by getting out of their seats to play or engage in other activities and then neglect to follow instructions. Student commitment and engagement in classroom activities promote learning and academic achievement, while noncompliant disruptive behavior, such as getting out of the seat, can result in negative indicators (Jensen, 2018). If this behavior is left unaddressed, it can increase a student's risk of continued behavior problems and poor grades (Finn \& Rock, 1997). Furthermore, students who demonstrate characteristics associated with attention difficulties often face academic challenges related to their inability to focus on a task and are less likely to meet academic or behavioral expectations (Fergusson, Lynskey, \& Horwood, 1997).

This research attempts to provide students with EBD and their teachers with interventions to help children display appropriate behaviors in the classroom and increase students' ability to focus on their tasks. 


\section{Research Question}

RQ 1: Does using opportunities to respond (OTR) interventions work to reduce disruptive behavior in the general education classroom?

\section{Literature Review}

In the United States (US), there are two regulations concerning appropriate services offered to students with emotional and behavioral disorders - the Individuals with Disabilities Education Improvement Act (IDEA) of 2004 and the No Child Left Behind Act (NCLBA) of 2001. The use of evidence-based interventions is mandated through these national laws and policies. Although evidence-based interventions are implemented in schools, the implementations often lack fidelity (Hallfors \& Godette, 2002). In combination, these regulations have had a significant effect on research aimed toward developing tiered approaches to school-based service delivery. These approaches are commonly known as response to intervention (RTI) models (Fuchs \& Fuchs, 2006). RTI models are early intervention approaches that evaluate children's responsiveness to evidence-based interventions implemented at three levels of increasing intensity as a basis for individualizing instruction and making eligibility decisions for students to receive special education services. In addition, according to Turnbull et al. (2016), RTI and multi-tiered systems of support (MTSS) - key components of ensuring accountability in education-have historically focused on the teaching and learning process. RTI is an alternative model of support that aims to systematically ensure that individuals who have special needs receive timely and effective support, providing intervention at an early stage when an individual first experiences academic difficulties.

Currently, teachers use various strategies to guide students with EBD; these include explicit instruction in addition to proactive and responsive behavior-management strategies. Research indicates that social and behavioral challenges faced by students with EBD interfere with the instructions given by teachers, leading to learning challenges (Nelson, Benner, \& Bohaty, 2014). Nelson, Benner, and Bohaty (2014) have also stated that teachers who work with students with EBD tend to focus more on behavior management over crucial academic instruction. Although the authors support enhancing teachers' knowledge of these behavioral mechanisms, they argue that teachers must directly integrate behavioral interventions with explicit instruction.

The intervention strategy for this study is the opportunities to respond (OTR) method. OTR refers to the opportunities given to students to respond individually or as a group to questions posed by a teacher (Sutherland, Alder, \& Gunter, 2003). MacSuga-Gage and Simonsen (2015) noted that to help students with EBD-including reducing disruptive behavior in general and in special education settings - teachers must consider active engagement as a key variable for both academic and behavioral success. The Council for Exceptional Children (CEC) has suggested an approximate frequency for OTR in the classroom. An opportunity to respond (OTR) is a situation where a teacher is interacting with the students by providing them the chance to give a response-for example, posing questions for students to answer by a nod, raising of hand, quick writing, or command (Cuticelli, Collier-Meek, \& Coyne, 2016). These opportunities could be presented to individual students or provided in a group setting. Opportunities to respond enhance interactivity between students and teachers, alertness, engagement, and understanding. Thus, OTR has been shown to improve students' outcomes (Cuticelli, CollierMeek, \& Coyne, 2016). For instance, the CEC has recommended four to six OTR per minute for students who have a high incidence of disabilities. However, in terms of fluency and maintenance levels, teachers should provide extra opportunities for students to practice (MacSuga-Gage \& Simonsen, 2015). Furthermore, Sutherland et al. (2003) found that when OTR increased, elementary students who exhibited disruptive behavior more often became involved in tasks, received praise, and received feedback. Most importantly, disruptive behavior decreased while responses from students increased. When teachers increased the use of OTR, the use of several other evidence-based practices also increased. For example, when teachers use OTR, they must provide students with feedback and praise; this means that when students respond more often, teachers should offer needed feedback and praise (Bolt, Hansen, Caldarella, Young, Williams, \& Wills, 2019). In addition, Bolt et al. (2019) have noted that OTR assists students in increasing on-task behavior as well as academic achievement in students with EBD.

There are many ways to reduce disruptive behavior, such as ensuring classroom or school environments that support appropriate behavior (Partin et al., 2009). This is achieved by having strategies that teacher uses, for example, teacher with instructions create more opportunities to have the students answer questions and tasks but remain in control of the class at the same time (Partin et al., 2009). A common example of teacher response is verbal, which includes calling on volunteers and calling on inattentive students. However, calling on volunteers is not recommended because the teacher may arrive at a situation where the same student, or small group of students, is most often responding. Another consequence of calling on volunteers is that disengaged students remain disengaged. However, calling on inattentive students may also create a situation where the student is "doomed to fail" because of their lack of concentration on the lesson. Instead, teachers should consider using more appropriate verbal response practices (Whitney, Cooper, \& Lingo, 2017). For instance, random selection can be an appropriate response. Random selection is useful because students are called on in a random fashion to 
respond to teacher questions without another consideration.

\section{Method}

Single-subject experimental design (SSED) appears to be an essential tool in the development of evidence-based practice in EBD. An A-B-A design was used in this study to locate the effect of OTR. In an A-B-A design, the researcher must first define both the target behavior and the appropriate intervention to be implemented. In A-BA, steps include collecting baseline data (A), introducing treatments (B), and then returning to the baseline phases (A) (Richards, 2018).

First, the dependent variable (noncompliant disruptive behavior which is specifically in this study getting out of seat) is measured repeatedly over time by frequency and recorded at regular intervals. In the second phase, the intervention is implemented, and student behavior is measured; frequency is recorded. After the intervention phase is completed, the researcher uses the same measure to determine whether the intervention was effective for the student. The researcher observes the students' five sessions during the first and last phases. In addition, there are five sessions of intervention in the second phase. Each session in each of the three phases is 21 minutes.

\section{Population}

The pseudonym used for the target student in this study was Miguel. Miguel was in the second grade and had EBD. Therefore, he spent two to three classes each day in the resource room with a special education teacher. Miguel had noncompliant disruptive behavior, and specifically, he moved out of his seat continuously throughout the school day. Typically, this meant he avoided finishing tasks by playing or engaging in another task, neglecting to follow instructions. He displayed this behavior in the general classroom more than in the resource room. However, he also displayed this behavior in the resource room, particularly when working in a group. For example, instead of writing or asking for help, he got out of his seat to talk or to gesture to his classmates, which meant that he was not completing the task required by his teacher.

The setting where the observation took place was the general classroom in an elementary school in Missouri, US. The school attendance area is large and includes many neighborhoods. It serves students from prekindergarten to sixth grade.

\section{Data Analysis Plan}

The type of data collected in this research was frequency. According to Mills and Gay (2015), frequency refers to the number of times something occurs; with descriptive statistics, frequency regularly describes how many times each value of a variable occurs. For example, in this study, the researcher wanted to know the number of times the subject got out of his seat in each observed session. This measure was used in all three phases of this A-B-A study.

For this type of analysis, the researcher uses the mean, which is a frequently used measure of central tendency. The mean is the calculation of the average of the scores. It is calculated by adding all the scores and dividing that total by the number of scores (Mills \& Gay, 2015). The researcher used this measure for all three phases of the present A-B-A study.

\section{Results}

For the indirect assessment, the student rate from Questions About Functional Behavior (QAFB) indicated different functions, but it clearly showed that the function of the student that is most in need of support is attention. In addition, the student's tangible behavior could be considered a function in need of support based on the rate of the QAFB. The student scored 12 points under attention, which was the highest result. He scored 11 points under tangible patterns, so this function could be considered his second function. The student scored 9 under escape patterns, which indicates that this function could be considered one of the student's functions. However, the student did not score at all regarding physical patterns.

In the direct observation to record the student's behavior using the frequency recording, the student showed that he was most likely to disrupt his classmates or teacher when his teacher asked him to do specific tasks such as reading. Aside from getting out of his seat, he was also likely to begin asking questions, especially when the teacher provided new instructions regarding a new task or provided new information to help students follow or better understand a current task. The student would then immediately ask his closest classmate about a specific issue or about what he should be doing.

The results of the first phase can be summarized as follows: he got out of his seat 13 times in the first and third sessions, 12 times in the second session, 10 times in the fourth session, and 12 times in the fifth session. To determine the baseline for the subject, the mean for the frequency was used. The mean in the stage was 12 times as 60 divided by five equals 12 . 


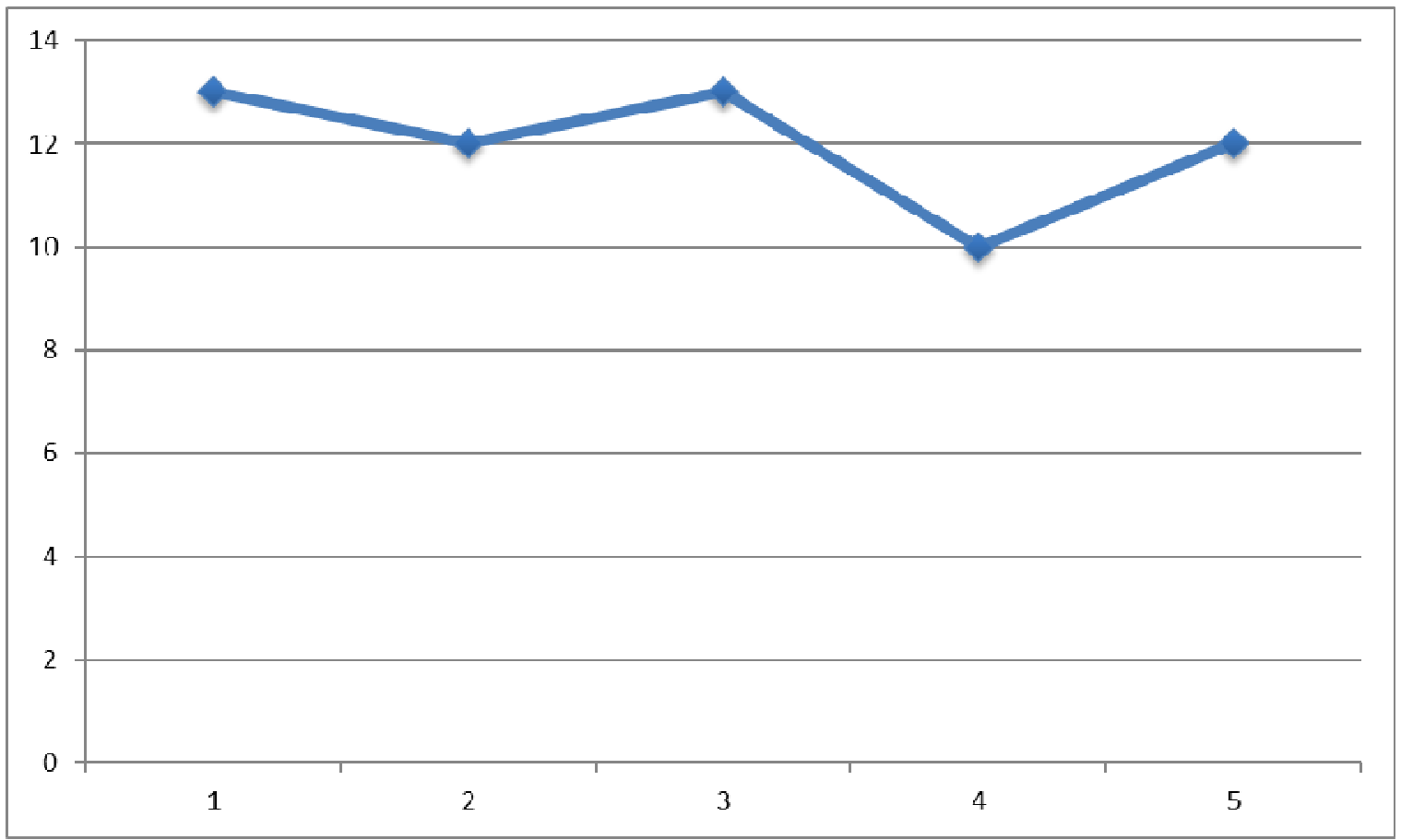

Figure 1. Results of Phase 1. Number of times out of seat (Y-Axis) per session (X-Axis).

In the second phase, intervention was implemented in the same classroom in which the subject was observed. The researcher used verbal responses, which included calling on volunteers and calling on inattentive students. The intervention lasted for 21 minutes each session, and the subject showed improvement in the intervention stage as follows: during the first session, the student got out of his seat 7 times, and on his second and third sessions, he got out of his seat five times. During the fourth session, he got out of his seat only four times, but he got out of his seat five times during the last session. The mean during all stages was 5.5 times, as 26 divided by five equal 5.5. This shows there was a clear positive change between the baseline stage and the intervention stage.

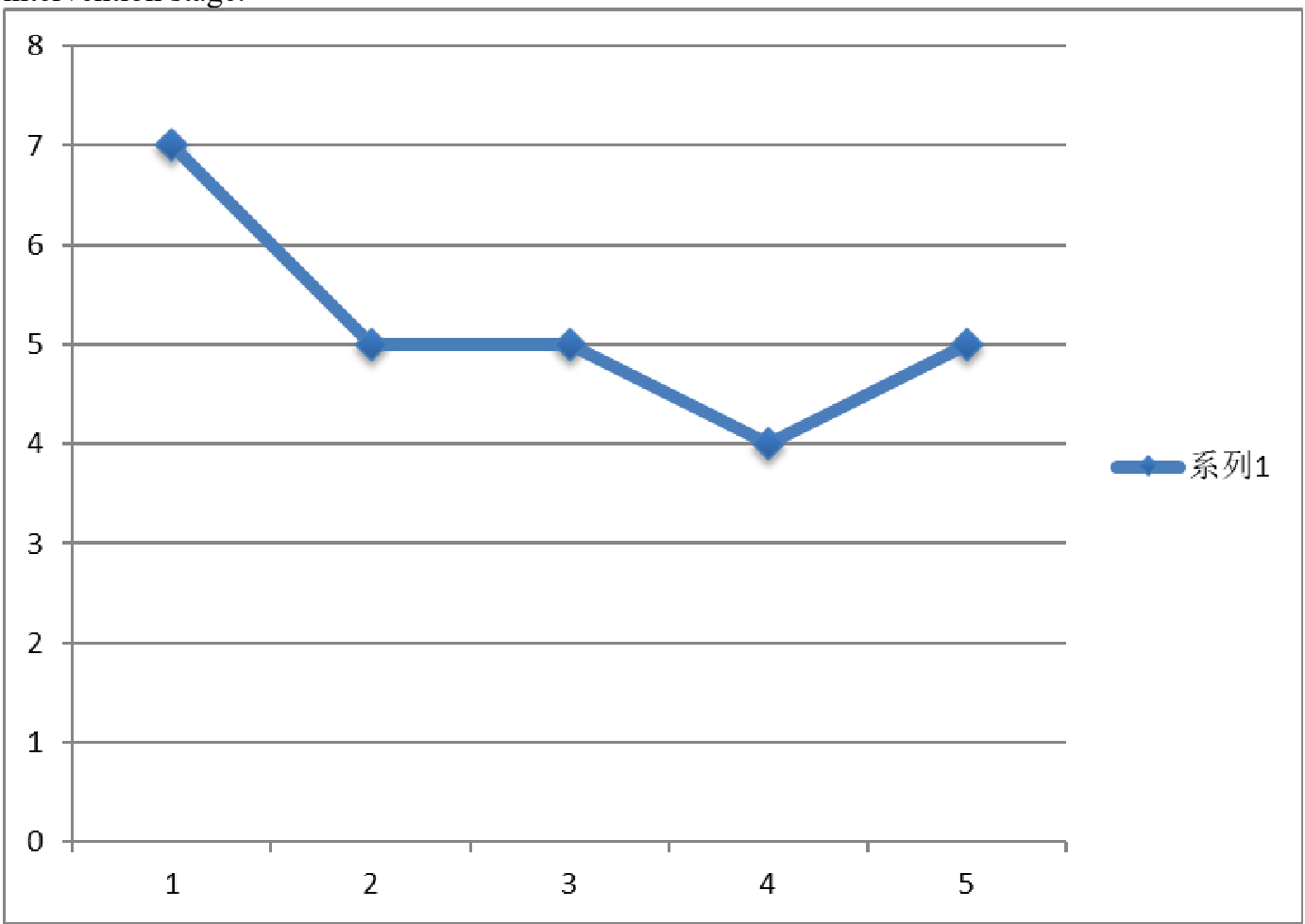

Figure 2. Results of Phase 2. Number of times out of seat (Y-Axis) per session (X-Axis).

During the final phase, the researcher observed students again without implementing the intervention. The first session after stopping the intervention was successful; the subject got out of his seat only four times during 
the first and second sessions. However, during the third session, he gets out of his seat six times, disturbing his classmates. During the fourth session, he got out of his seat six times. Unfortunately, the researcher could not observe the subject during the fifth session for several reasons, including that the subject was absent for special training. However, the other four sessions revealed that the mean for this frequency was five.

This strategy was effective and showed that the student improved in terms of staying in his seat working with his classmates as instructed. However, the subject was not seated all the required time and did not always follow the teacher's instructions, resulting in disturbing his classmates.

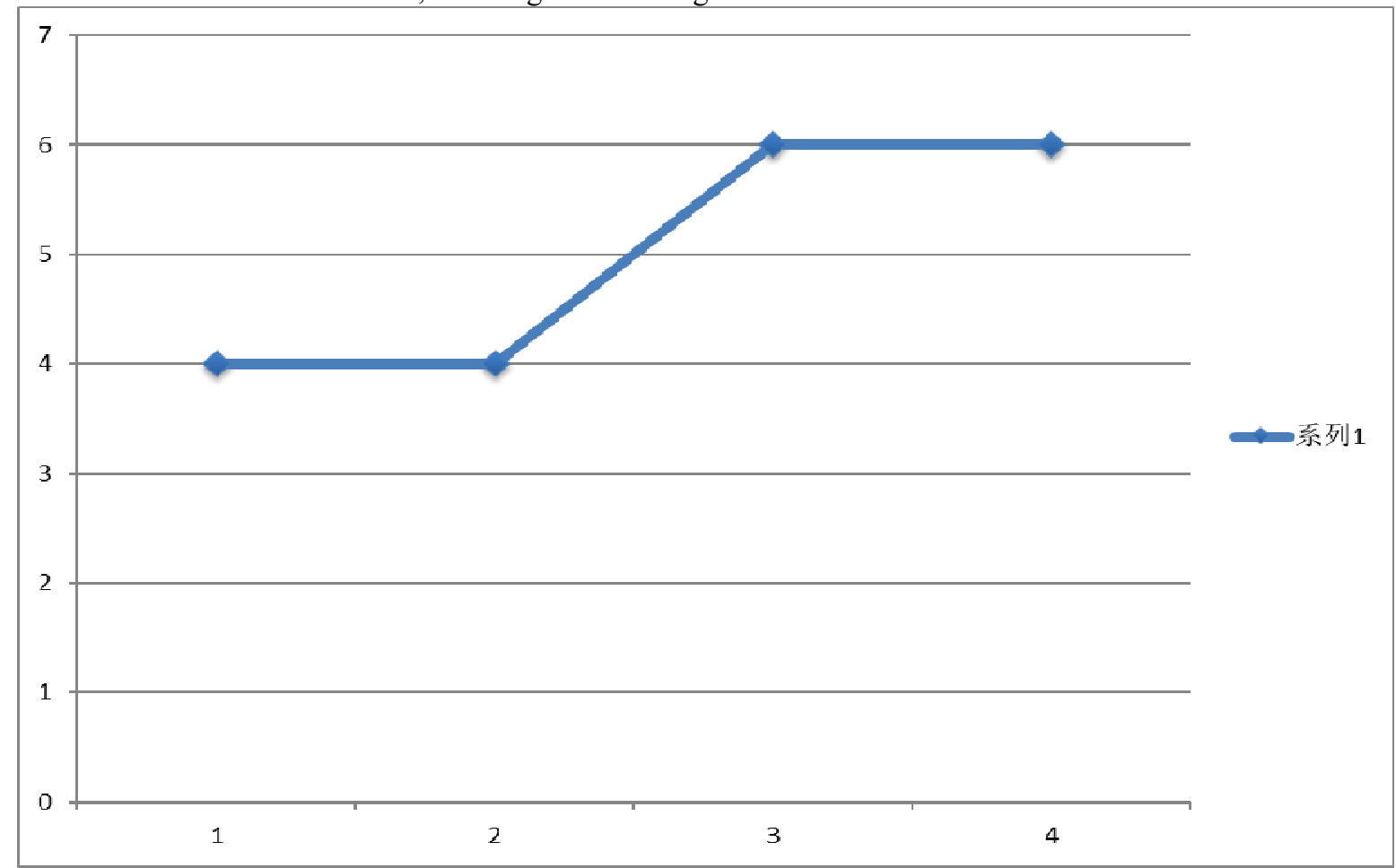

Figure 3. Results of Phase 3. Number of times out of seat (Y-Axis) per session (X-Axis).

\section{Discussion and Conclusion}

All the above research included in the literature review suggests that teachers should use OTR only if they are providing an adequate number of opportunities during instruction. OTR has been shown to create a positive impact on students in terms of both academic achievement and behavior problems. OTR also provides students with a better strategy than the traditional strategies that do not involve providing numerous opportunities for students to respond in a classroom setting and ultimately become successful students. EBDs can deprive students of the opportunity to succeed in the classroom by distracting them and their surrounding classmates from the learning process that is being presented by the teacher.

The OTR intervention outlined in this study was effective, and the third phase showed the improvement made by the student; however, one limitation of this study was the time limits. Another point is that the researcher recommends using A-B-A-B design in the future study instead of A-B-A design because A-B-A-B design will allow the researchers to reapply the same steps one more time to have more confidence about the results.

\section{References}

Bolt, T. D., Hansen, B. D., Caldarella, P., Young, K. R., Williams, L., \& Wills, H. P. (2019). Varying opportunities to respond to improve behavior of elementary students with developmental disabilities. International Electronic Journal of Elementary Education, 11(4), 327-334. https://doiorg.ezp.slu.edu/10.26822/iejee.2019450791

Bradshaw, C. P., Buckley, J., \& Ialongo, N. (2008). School-based service utilization among urban children with early-onset educational and mental health problems: The squeaky wheel phenomenon. School Psychology Quarterly, 23(2), 169-186.

Cuticelli, M., Collier-Meek, M., \& Coyne, M. (2016). Increasing the quality of tier 1 reading instruction: Using performance feedback to increase opportunities to respond during the implementation of a core reading program. Psychology in the Schools, 53(1), 89-105.

Finn, J. D., \& Rock, D. A. (1997). Academic success among students at risk for school failure. Journal of 
Applied Psychology, 82(2), 221-234. doi:10.1037/0021-9010.82.2.221

Fergusson, D. M., Lynskey, M. T., \& Horwood, L. J. (1997). Attentional difficulties in middle childhood and psychosocial outcomes in young adulthood. Journal of Child Psychology and Psychiatry, 38(6), 633-644. doi:10.1111/j.1469-7610.1997.tb01690.x

Fuchs, D., \& Fuchs, L. S. (2006). Introduction to response to intervention: What, why, and how valid is it? Reading Research Quarterly, 41(1), 93-99. http://search.ebscohost.com.ezp.slu.edu/login.aspx?direct=true\&db=eric\&AN=EJ780372\&site=ehost-live

Hallfors, D. D., \& Godette, D. D. (2002). Will the 'principles of effectiveness' improve prevention practice? Early findings from a diffusion study. Health Education Research, 17(4), 461-470.

Jensen, J. (2018). Promoting appropriately engaged behavior in the classroom with student self-monitoring and teacher feedback [Master's thesis]. California State University Monterey Bay Digital Commons (299).

MacSuga-Gage, A. S., \& Simonsen, B. (2015). Examining the effects of teacher-directed opportunities to respond on student outcomes: A systematic review of the literature. Education and Treatment of Children, 38(2), 211-239. doi:10.1353/etc.2015.0009

Mills, Geoffrey E.; Gay, L. R. (2015). Educational research: Competencies for analysis and applications (Page 6). Pearson Education.

Nelson, J. R., Benner, G. J., \& Bohaty, J. (2014). Addressing the academic problems and challenges of students with emotional and behavioral disorders. In H. M. Walker and F. M. Gresham (Eds.), Handbook of evidence-based practices for emotional and behavioral disorders (pp. 363-377). The Guilford Press.

Partin, T. C. M., Robertson, R. E., Maggin, D. M., Oliver, R. M., \& Wehby, J. H. (2009). Using teacher praise and opportunities to respond to promote appropriate student behavior. Preventing School Failure: Alternative Education for Children and Youth, 54(3), 172-178.

Sutherland, K. S., Alder, N., \& Gunter, P. L. (2003). The effect of varying rates of opportunities to respond to academic requests on the classroom behavior of students with EBD. Journal of Emotional and Behavioral Disorders, 11(4), 239-248. doi:10.1177/10634266030110040501

Seeley, J. R., Severson, H. H., \& Fixsen, A. A. (2014). Empirically based targeted prevention approaches for addressing externalizing and internalizing behavior disorders within school contexts. In H. M. Walker and F. M. Gresham (Eds.), Handbook of evidence-based practices for emotional and behavioral disorders (pp. 307-323). The Guilford Press.

Turnbull, A., Turnbull, R., Wehmeyer, M., \& Shogren, K. (2016). Exceptional lives: Special education in today's schools (8th ed.). Pearson.

Whitney, T., Cooper, J. T., \& Lingo, A. S. (2017). Increasing student engagement through opportunities to respond. Kentucky Teacher Education Journal: The Journal of the Teacher Education Division of the Kentucky Council for Exceptional Children, 3(2). https://digitalcommons.wku.edu/ktej/vol3/iss2/3/

Richards, Stephen B. (2018). Single subject research: Applications in educational settings. 